\title{
Combination of non-viral connexin 43 gene therapy and docetaxel inhibits the growth of human prostate cancer in mice
}

\author{
MASAYOSHI FUKUSHIMA, YOSHIYUKI HATTORI, TAKASHI YOSHIZAWA and YOSHIE MAITANI \\ Institute of Medicinal Chemistry, Hoshi University, Shinagawa-ku, Tokyo 142-8501, Japan
}

Received August 24, 2006; Accepted November 23, 2006

\begin{abstract}
Docetaxel (DTX) is used for the treatment of advanced hormone refractory prostate cancer. Connexin 43 (Cx43) is a tumor suppressor gene, and transfection of the Cx43 gene increases sensitivity to several chemotherapeutic agents. The objective of this study was to evaluate the effectiveness of combination therapy of $\mathrm{Cx} 43$-expressing plasmid DNA (pCMV-Cx43) and DTX both in vitro and in vivo using a non-viral vector in human prostate cancer PC-3 cells. Transfection of pCMV-Cx43 into the cells neither inhibited tumor growth nor increased gap junctional intercellular communication; however, combination therapy of pCMVCx43 and DTX significantly inhibited cell growth. Forced expression of $\mathrm{Cx} 43$ in the cells induced apoptotic cells by down-regulation of Bcl-2 expression and significantly more up-regulation of caspase- 3 activity than either treatment alone. The combination of repeated intratumoral injection of pCMV-Cx43 (10 $\mu \mathrm{g} /$ tumor) with non-viral vector and a single intravenous injection of DTX $(15 \mathrm{mg} / \mathrm{kg})$ was compared with a repeated injection of $\mathrm{Cx} 43$ alone and a single injection of DTX alone on PC-3 tumor xenografts. Significant antitumoral effects were observed in mice receiving combined treatment, compared with DTX alone. The data presented here provide a rational strategy for treating patients with advanced hormone refractory prostate cancer.
\end{abstract}

\section{Introduction}

Prostate cancer is a significant problem and is reported to be the leading cancer diagnosed in man (1). Cytotoxic chemotherapy has shown significant palliative benefit in the treatment of androgen-independent prostate cancer, but with no survival advantage demonstrated to date (2). Current chemotherapy is limited by drug tolerance and the ultimate emergence of resistant disease (3). Novel approaches incor-

Correspondence to: Professor Yoshie Maitani, Institute of Medicinal Chemistry, Hoshi University, Shinagawa-ku, Tokyo 1428501, Japan

E-mail: yoshie@hoshi.ac.jp

Key words: prostate cancer, connexin 43, docetaxel, PC-3 cells, cytotoxicity, gene therapy, non-viral vector, combination therapy porating potentially more active and less toxic agents that may overcome drug resistance mechanisms need to be investigated. Increased understanding of the tumor biology of prostate cancer offers promise of novel treatments for this disease.

Docetaxel (DTX), a member of the taxane family, is semisynthesized from an inactive taxoid precursor extracted from the needles of the European yew, Taxus baccata. DTX has shown clinical activity in a wide spectrum of solid tumors including breast, lung, ovarian, and prostate cancers $(4,5)$. The known basic cellular target of DTX is the microtubule. Furthermore, DTX down-regulates genes for cell proliferation, mitotic spindle formation, transcription factor, and oncogenesis, and up-regulates genes related to the induction of apoptosis and cell cycle arrest in prostate cancer PC-3 and LNCaP cells $(6,7)$.

Connexins (Cxs) are a family of transmembrane proteins that enable gap junctional intercellular communication (GJIC) (8). GJIC is one mechanism of growth control that involves cell-cell contact (9). In general, cancer cells exhibit altered Cxs expression, with a profile that is often significantly reduced or undetectable. Connexin $43(\mathrm{Cx} 43)$ and connexin 32 (Cx32) expressions were reduced in prostate tumor biopsy in contrast to normal prostate epithelial cells (10-13). Since Cx43 is a tumor-suppressor gene, $\mathrm{Cx} 43$ gene therapy was reported (14-16). Transfection of Cx43 in human mammary carcinoma MDA-MB-435 cells (17), human glioblastoma U251 and T98G cells (16), lung cancer PG cells (18) and prostate cancer LNCaP cells (19) significantly reduces cell growth in vitro and/or in vivo. Transfection of Cx43 in human glioblastoma U251 cells (20) and ovarian carcinoma SKOV-3 cells (21) increased sensitivity to several chemotherapeutic agents. However, the effect of transfection of the $\mathrm{Cx}$ gene combined with DTX on prostate tumor PC-3 cells has not been reported to our knowledge.

In this study, we investigated whether the transfection of plasmid DNA (pCMV-Cx43) coding for the Cx43 gene by non-viral vector combined with DTX increased the inhibition of PC-3 cell growth. A novel combination of pCMV-Cx43 and DTX induced significantly greater growth inhibition in PC-3 cells and tumor xenografts than DTX alone. This combination increased apoptosis via the down-regulation of Bcl-2 expression and up-regulation of caspase-3 activity.

\section{Materials and methods}

Cell culture. PC-3 and LNCaP cells were supplied by the Cell Resource Center for Biomedical Research, Tohoku University. 
PC-3 and LNCaP cells were grown in RPMI-1640 medium supplemented with $10 \%$ heat-inactivated fetal bovine serum (FBS) and kanamycin $(100 \mu \mathrm{g} / \mathrm{ml})$ at $37^{\circ} \mathrm{C}$ in a $5 \% \mathrm{CO}_{2}$ humidified atmosphere.

Plasmid constructions. Plasmid pCMV-Cx43 encoding the $\mathrm{Cx} 43$ gene under the control of CMV promoter was constructed as previously described (22). Plasmid pCMV-luc encoding the luciferase gene under the control of the CMV promoter was constructed as previously described (23). pGL3-basic (Promega, Madison, WI) was used as a control plasmid. A protein-free preparation of the plasmid was purified following alkaline lysis using maxiprep columns (Qiagen, Hilden, Germany).

Sensitivity to DTX assay. PC-3 and LNCaP cells were seeded separately at a density of $1 \times 10^{4}$ cells per well in 96-well plates and maintained for $24 \mathrm{~h}$ before transfection in RPMI medium supplemented with $10 \%$ FBS. Cells at $30 \%$ confluence in the well were transfected with $0.2 \mu \mathrm{g}$ of pCMV-Cx43 or pGL3-basic using lipofectamine 2000 (Invitrogen Corp., Carlsbad, CA) according to the manufacturer's instructions and incubated for $24 \mathrm{~h}$. The culture medium was then exchanged to medium containing various concentrations of DTX (Taxotere, Sanofi-Aventis, Paris, France) ranging from 0.1 to $1,000 \mathrm{ng} / \mathrm{ml}$ and incubated for another $48 \mathrm{~h}$. In co-transfection, cells were transfected with $0.2 \mu \mathrm{g}$ of pCMV-Cx43 or pGL3-basic using lipofectamine 2000 in medium containing DTX $(0.1-1,000 \mathrm{ng} /$ $\mathrm{ml}$ ) and incubated for $72 \mathrm{~h}$. The cell number was determined with WST-8 assay (Dojindo Laboratories, Kumamoto, Japan).

Fluorescent dye transfer. FACS analysis of the GJIC reported by Robe et al (24) was modified. Briefly, cells grown in 35-mm dishes were labeled for 1-h incubation with either $5 \mu \mathrm{M}$ calceinAM (acetomethylic ester, Dojindo) or $5 \mu \mathrm{M}$ DiI (Lambda Probes \& Diagnostics, Graz, Austria) in the medium. The two labeled cells were mixed in equal proportions in $35-\mathrm{mm}$ dishes and incubated for $12 \mathrm{~h}$. Subsequently, pCMV-Cx43 or pGL3-basic was transfected into mixed cells in the presence or absence of $50 \mu \mathrm{M} 18 \alpha$-glycyrrhethinic acid (18GA, MP Biomedicals, Germany). After 24-h incubation, the cells were trypsinized, washed in phosphate-buffered saline $\mathrm{pH} 7.4$ (PBS), and processed for FACS analysis of calcein-AM and DiI fluorescence with a FACSCalibur flow cytometer as previously reported (22). Data for 10,000 fluorescent events were obtained by calcein-AM fluorescence $(530 / 30 \mathrm{~nm})$ and DiI fluorescence (585/42).

Cell cycle analysis. PC-3 cells were seeded at a density of $1 \times 10^{6}$ cells on $35-\mathrm{mm}$ dishes. Cells were transfected with pCMV-Cx43 or pGL3-basic in the presence or absence of $10 \mathrm{ng} / \mathrm{ml}$ DTX in medium. After 24-h incubation, the cells were harvested with EDTA after washing with ice-cold PBS. Detached cells were washed once with ice-cold PBS and gently suspended in PBS-EtOH $(70 \%)$ and fixed overnight at $4^{\circ} \mathrm{C}$. For staining, fixed cells were washed once in PBS and then resuspended in PBS with $50 \mu \mathrm{g} / \mathrm{ml}$ propidium iodide (PI) and $0.5 \%$ RNase A. After $30 \mathrm{~min}$ at $37^{\circ} \mathrm{C}$, cells were processed for FACS analysis of PI fluorescence by a FACSCalibur flow cytometer as described in the above section.
Western blotting. PC-3 cells were seeded at a density of $1 \times 10^{6}$ cells on $35-\mathrm{mm}$ dishes. Cells were transfected with pGL3-basic or pCMV-Cx43, respectively. Twenty-four hours after transfection, the culture medium was replaced with medium containing $10 \mathrm{ng} / \mathrm{ml}$ DTX and incubated for $24 \mathrm{~h}$. Cells were suspended in lysis buffer (1\% Triton-X 100 and protease inhibitor cocktail set III (Calbiochem, Darmstadt, Germany) in PBS), and then centrifuged at 15,000 rpm for 10 min. The supernatants were resolved on a $15 \%$ sodium dodecyl sulphate-polyacrylamide gel by electrophoresis (SDSPAGE) and transferred to a polyvinylidene difluoride (PVDF) membrane (FluoroTrans ${ }^{\circledR}$ W, PALL Gelman Laboratory, Ann Arbor, MI). Expression of $\mathrm{Cx} 43, \mathrm{Bcl}-2$ and $\mathrm{B}$-actin protein was identified using rabbit anti-Cx43 polyclonal antibody (Sigma, St. Louis, MO), rabbit anti-Bcl-2 polyclonal antibody (Stressgen, Canada) or rabbit anti- $\beta$-actin polyclonal antibody (Lab Vision, CA), respectively. Goat anti-rabbit IgG peroxidase conjugate (Santa Cruz Biotechnology, Inc., Santa Cruz, CA) was used as the secondary antibody. These proteins were detected with peroxidase-induced chemiluminescence (Super Signal West Pico Chemiluminescent Substrate, Pierce). Optical density of the bands on the film was quantified using ImageQuant TL (Amersham Biosciences, NJ) with correction for the optical density of the corresponding $\beta$-actin band.

Apoptosis analysis. PC-3 cells were seeded at a density of $1 \times 10^{6}$ cells on $35-\mathrm{mm}$ dishes. The cells were transfected with pGL3-basic or pCMV-Cx43, respectively. Twenty-four hours after transfection, the culture medium was replaced with medium containing $10 \mathrm{ng} / \mathrm{ml}$ DTX and incubated for $24 \mathrm{~h}$. Apoptotic cells were detected with an annexin V-FITC apoptosis detection kit (Sigma) or caspase-3 apoptosis detection kit (Santa Cruz Biotechnology) according to the manufacturer's instructions.

Assessment of PC-3 tumor growth. For transfection in vivo, we prepared cationic nanoparticle (NP) as previously reported (25). Briefly, NP was formulated using $1 \mathrm{mg} / \mathrm{ml}$ cholesteryl$3 ß$-carboxyamidoethylene- $N$-hydroxyethylamine (OH-Chol) as a cationic lipid, and $5 \mathrm{~mol} \%$ Tween-80, and was prepared in $10 \mathrm{ml}$ of water by the modified ethanol injection method (25).

Male BALB/c nu/nu mice (6-8 weeks of age) were purchased from CLEA Japan Inc. (Tokyo, Japan). To generate PC-3 tumor xenografts, $1 \times 10^{7} \mathrm{PC}-3$ cells suspended in $50 \mathrm{ml}$ of medium containing $60 \%$ reconstituted basement membrane (Matrigel: Collaborative Research, Bedford, MA) were inoculated subcutaneously into the flank region of the mice. Tumor volume was calculated using the formula, tumor volume $=0.5 a b^{2}$, where $a$ and $b$ are the larger and smaller diameters, respectively. When the average volume of PC-3 xenograft tumors reached $200 \mathrm{~mm}^{3}$ (day 0), these mice were selected for treatment with DTX alone, pGL3-basic, pCMV-Cx43, pGL3-basic plus DTX, and pCMV-Cx43 plus DTX. For transfection into tumors, the nanoplex was formed by the addition of NP $(15.8 \mu \mathrm{l})$ to $10 \mu \mathrm{g}$ of pCMV-Cx43 or pGL3basic with gentle shaking and standing at room temperature for $10 \mathrm{~min}$. Nanoplexes of $10 \mu \mathrm{g}$ plasmid per tumor were directly injected into xenografts on days 0 and 1. DTX at a dose of $15 \mathrm{mg} / \mathrm{kg}$ was injected i.v. on day 0 . Tumor volume was measured on days $0,3,6,9,11,13,15$. On day 15 , all 
$\mathbf{A}$

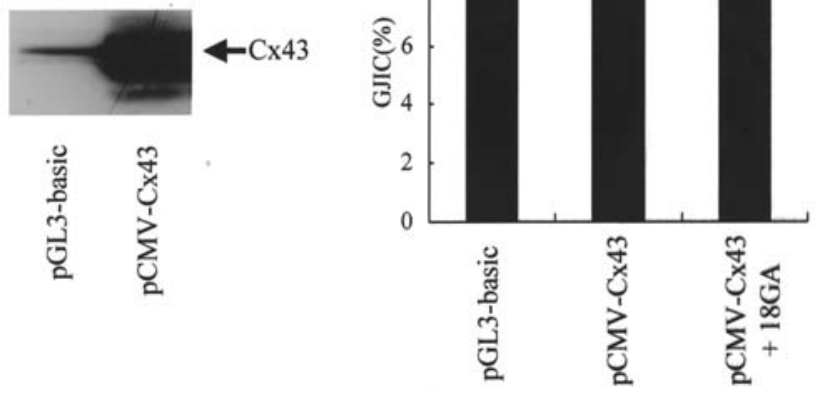

Figure 1. Cx43 expression and GJIC transfected with pCMV-Cx43 in PC-3 cells. (A) Western blot analyses of $\mathrm{Cx} 43$ in the cells $24 \mathrm{~h}$ after transfection with pCMV-Cx43 or pGL3-basic. (B) Effect of Cx43 transfection on gap junctional intercellular communication (GJIC) analyzed by flow cytometry. Calcein-AM-labeled cells were mixed with DiI-labeled cells, and transfected with pCMV-Cx 43 or pGL3-basic. Cells were incubated for $24 \mathrm{~h}$ in the presence or absence of $50 \mu \mathrm{M} 18 \mathrm{GA}$.

mice were sacrificed after anesthetization by i.m. injection of pentobarbital (Nembutal, Dainippon Pharmaceutical Co., Ltd., Osaka, Japan), and the tumor weights were measured. The data are shown as the mean $\pm \mathrm{SE}$. Animal experiments were conducted with ethical approval from our institutional animal care and use committee.

Statistical analysis. The statistical significance of the data was evaluated with Student's t-test. A $\mathrm{P} \leq 0.05$ was considered significant.

\section{Results}

Effect of Cx43 expression on PC-3 cells. We initially characterized the expression of $\mathrm{Cx} 43$ in PC-3 cells. In this study, we used pGL3-basic as a control plasmid. Cx43 expression was observed strongly in pCMV-Cx43-transfected cells, but weakly in pGL3-basic-transfected cells (Fig. 1A). Next, we examined whether the transfection of pCMV-Cx43 induced growth inhibition in the cells. Seventy-two hours after transfection, $\mathrm{Cx} 43$ expression did not significantly induce a suppressive effect in PC-3 cells (data not shown).

To investigate whether the expression of $\mathrm{Cx} 43$ protein by pCMV-Cx 43 caused the formation of gap junctions, we assessed the transfer of calcein-AM, a cytoplasmic dye that crosses gap junctions, in co-culture with calcein-AM-loaded cells and cells marked with DiI, a non-diffusible membrane fluorescent dye, by FACS analysis. As shown in Fig. 1B, GJIC (\%) was not significantly increased in pCMV-Cx43-transfected cells compared with pGL3-basic-transfected cells. Moreover, pCMV-Cx 43 -transfected cells treated with 18GA, GJIC inhibitor did not decrease either the GJIC (\%) compared with pGL3-basic- or pCMV-Cx43-transfected cells (Fig. 1B).

In vitro sensitivity of DTX. To evaluate the in vitro growth inhibitory effect of combination therapy of $\mathrm{Cx} 43$ and DTX, the WST-8 assay was initially performed. When PC-3 cells were transfected with pGL3-basic or pCMV-Cx43 in the presence of DTX, pCMV-Cx43-transfected cells $\left(\mathrm{IC}_{50}=1.1 \mathrm{ng} / \mathrm{ml}\right)$ showed 53-fold higher sensitivity to DTX than pGL3-basic-transfected cells $\left(\mathrm{IC}_{50}=58.7 \mathrm{ng} / \mathrm{ml}\right)$ (Fig. $\left.2 \mathrm{~A}\right)$. However, when PC-3 cells were treated with DTX $24 \mathrm{~h}$ after the transfection of pGL3-basic or pCMV-Cx43, pCMV-Cx43-transfected cells $\left(\mathrm{IC}_{50}=1.4 \mathrm{ng} / \mathrm{ml}\right)$ showed 279 -fold higher sensitivity to DTX than pGL3-basic-transfected cells $\left(\mathrm{IC}_{50}=390.0 \mathrm{ng} / \mathrm{ml}\right)$ (Fig. 2B). When PC-3 cells were transfected with pCMV-Cx43 $24 \mathrm{~h}$ after treatment with DTX, cytotoxicity could not be evaluated since cells were almost dead even at $1 \mathrm{ng} / \mathrm{ml}$ of DTX (data not shown). Therefore, in subsequent in vitro experiments, the cells were treated with DTX $24 \mathrm{~h}$ after transfection of pCMV-Cx43.
A

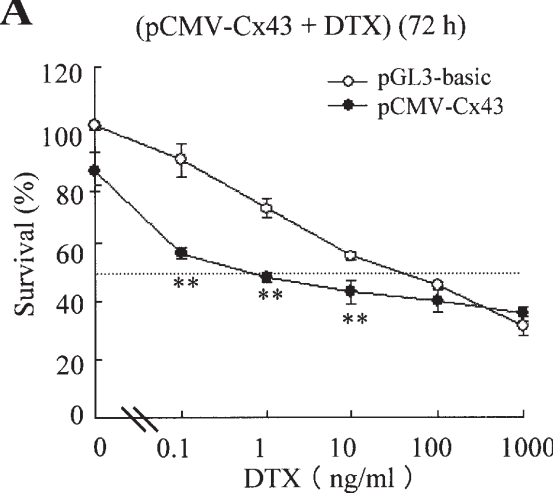

B

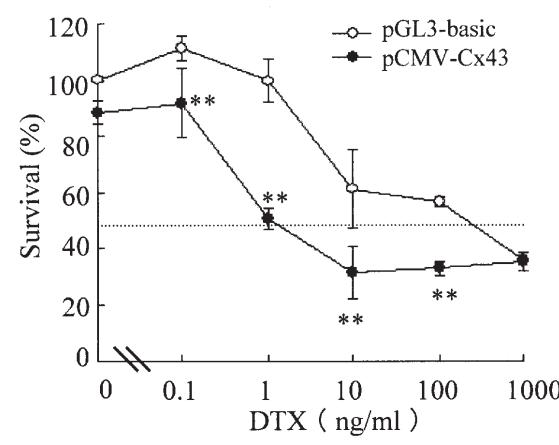

\begin{tabular}{ccr}
\hline & $\mathrm{IC}_{50}(\mathrm{ng} / \mathrm{ml})$ & $(\%)$ \\
\hline pGL3-basic & 390.0 & 100.0 \\
pCMV-Cx43 & 1.4 & 0.4 \\
\hline
\end{tabular}

Figure 2. Concentration-dependent effect of DTX on cytotoxicity in Cx43-transfected cells. (A) Cells were transfected with $0.2 \mu \mathrm{g}$ of pCMV-CX43 or pGL3basic in the presence of DTX and incubated for $72 \mathrm{~h}$. (B) PC-3 cells were transfected with pCMV-Cx43 or pGL3-basic for 24 h. After incubation, cells were treated with various concentrations of DTX and incubated for another $48 \mathrm{~h}$. The number of viable cells was determined by WST-8 assay. $\mathrm{n}=3 \mathrm{for}$ each sample. ${ }^{* *} \mathrm{p}<0.01$; compared with pGL3-basic. 
A

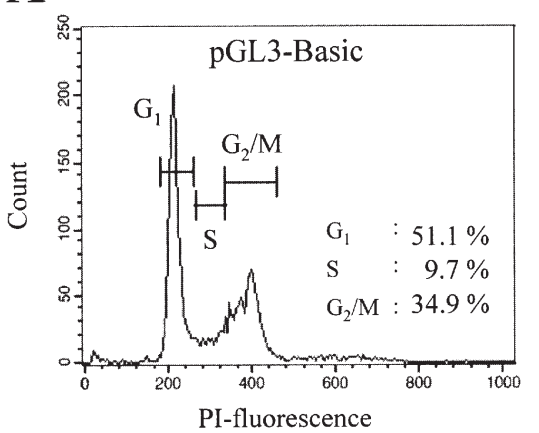

C

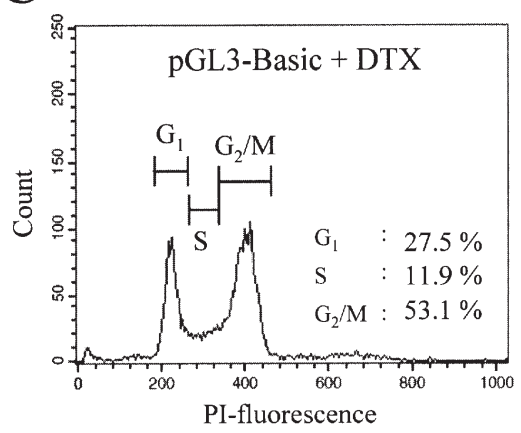

B

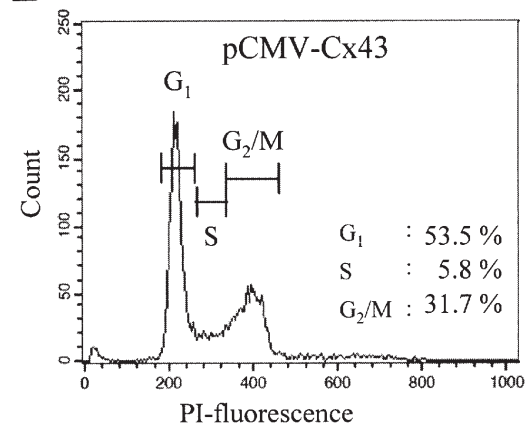

D

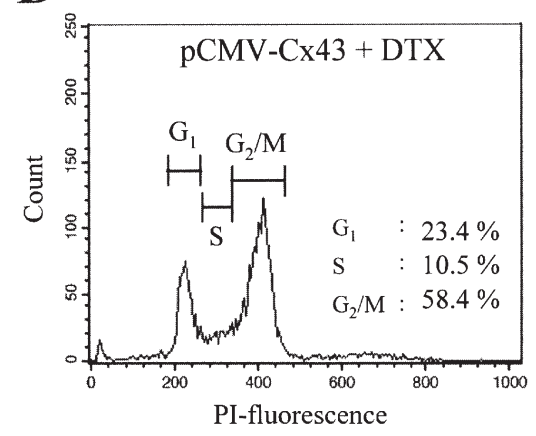

Figure 3. Cell cycle kinetics of pGL3-basic (A), pCMV-Cx43 (B), pGL3-basic plus $10 \mathrm{ng} / \mathrm{ml}$ DTX (C), and pCMV-Cx43 plus $10 \mathrm{ng} / \mathrm{ml}$ DTX (D) $24 \mathrm{~h}$ after transfection into PC-3 cells. Histograms illustrate the differences in $\mathrm{G}_{1}, \mathrm{~S}$, and $\mathrm{G}_{2} / \mathrm{M}$ phases upon transfection into PC-3 cells.

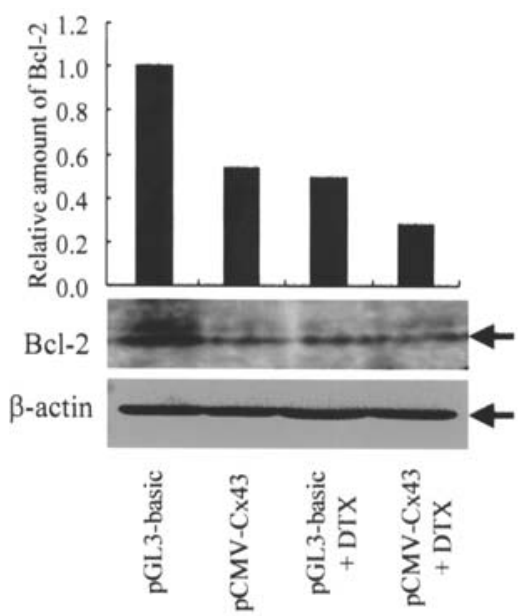

Figure 4. Decrease of Bcl-2 expression in PC-3 cells by combination therapy of Cx43 and DTX. Cells were transfected with pGL3-basic or pCMV-Cx43 for $24 \mathrm{~h}$. Culture medium was replaced with medium containing of $10 \mathrm{ng} / \mathrm{ml}$ DTX and incubated for another $24 \mathrm{~h}$. Bcl-2 expression was examined by Western blot analyses, quantified using densitometry.

We next assessed the effect of pCMV-Cx43 and DTX on the cell cycle $24 \mathrm{~h}$ after transfection into PC-3 cells by flow cytometric analysis. Transfection of pCMV-Cx43 into the cells did not affect the cell cycle (Fig. 3A and B), but DTX caused an increase in $\mathrm{G}_{2} / \mathrm{M}$ populations (53.1\%) (Fig. 3C). Co-transfection of pCMV-Cx43 with DTX resulted in substantial accumulation in $\mathrm{G}_{2}(58.4 \%)$ populations (Fig. 3D).

Effect of Bcl-2 expression and apoptosis activity on PC-3 cells. Recently, it has been reported that transfection of $\mathrm{Cx}$ down-regulated the levels of Bcl-2 (20,26,27). Therefore, to investigate whether transfection with $\mathrm{pCMV}-\mathrm{Cx} 43$ and/or treatment with DTX affected Bcl-2 expression in PC-3 cells, we examined the levels of protein expression of $\mathrm{Bcl}-2$ in the cells by Western blotting. Either pCMV-Cx43-transfection or DTX treatment down-regulated the levels of Bcl-2 (Fig. 4). Moreover, pCMV-Cx43-transfected cells treated with DTX exhibited the most down-regulated level of Bcl-2 compared with pGL3-basic-transfected cells (Fig. 4).

Next, we examined the apoptotic effect in cells transfected with $\mathrm{Cx} 43$ and/or treated with DTX by annexin V assay. As shown in Fig. 5A, pCMV-Cx43 transfection or treatment with DTX increased apoptosis in the cells compared with pGL3-basic transfection. Moreover, the incidence of apoptosis was highest in pCMV-Cx43-transfected cells treated with DTX.

To investigate the apoptosis mechanism by combination therapy of Cx43 and DTX, we measured caspase- 3 activity. As shown in Fig. 5B, caspase-3 activity in pCMV-Cx43transfected cells, pGL3-basic-transfected cells with DTX and pCMV-Cx43-transfected cells with DTX was 1.6-, 1.4- and 2.0-fold higher than that in pGL3-basic-transfected cells, respectively. Forced expression of $\mathrm{Cx} 43$ in the cells induced significantly more up-regulation of caspase- 3 activity than either treatment alone. These results suggest that the constitutive expression of $\mathrm{Cx} 43$ may play a role in the enhancement of apoptosis by chemotherapeutic agents.

Synergistic inhibition of the growth of PC-3 tumor xenografts. The efficacy of combination therapy of Cx43 and DTX in inhibiting the growth of subcutaneous PC-3 tumors was evaluated. We previously reported that NP could efficiently 
$\mathbf{A}$

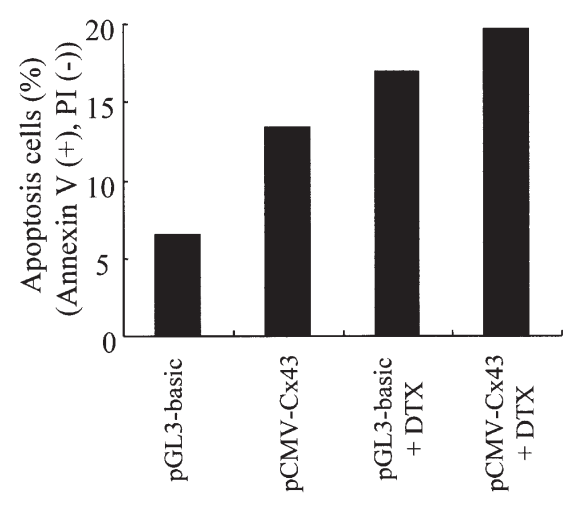

B

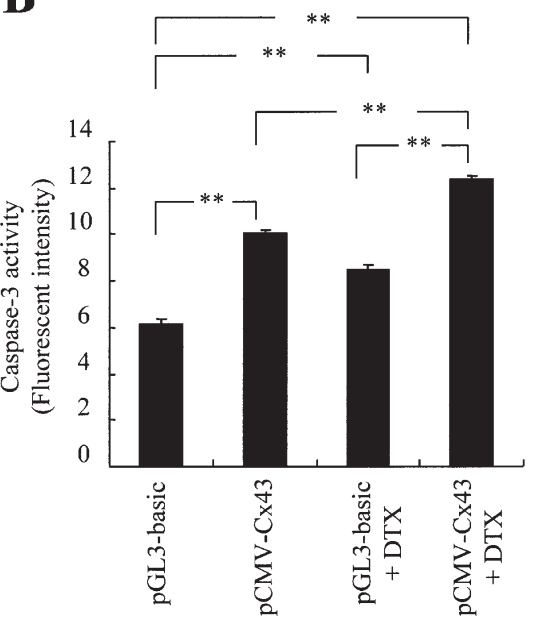

Figure 5. Apoptotic cells and caspase-3 activity by combined treatment with CX43 and DTX on PC-3 cells. Cells were transfected with pGL3-basic or pCMV-Cx43 and incubated for $24 \mathrm{~h}$. Culture medium was replaced with medium containing $10 \mathrm{ng} / \mathrm{ml}$ DTX, and incubated for another $24 \mathrm{~h}$. Apoptotic cells and caspase-3 activity were detected by annexin $\mathrm{V}$ assay (A) and caspase-3 fluorometric assay (B). (B), $\mathrm{n}=3$ for each sample. ${ }^{* *} \mathrm{p}<0.01$.
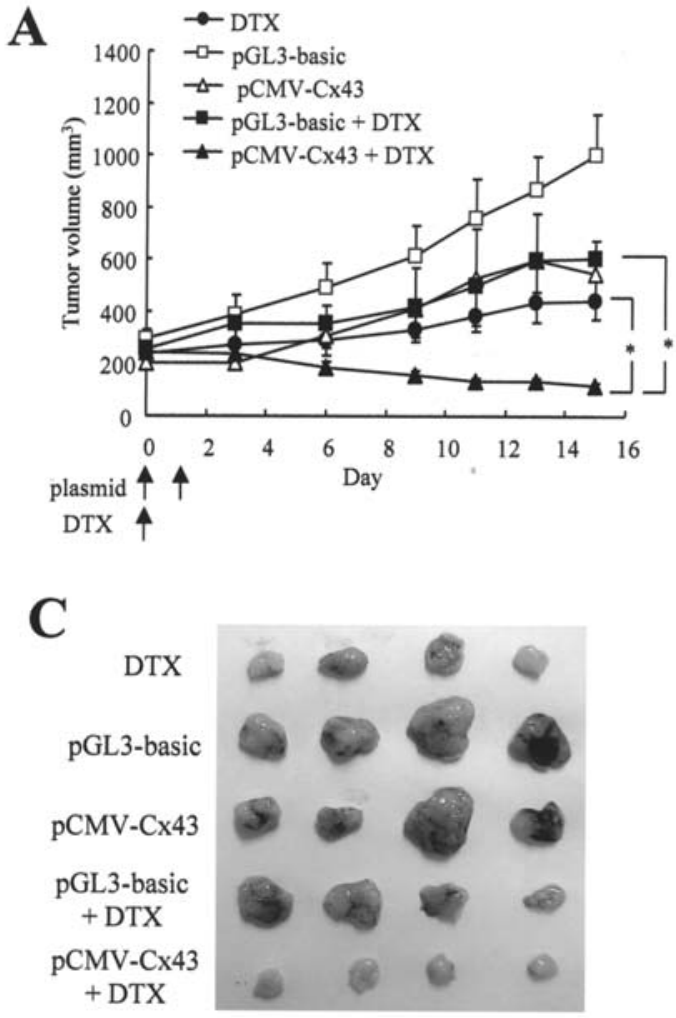

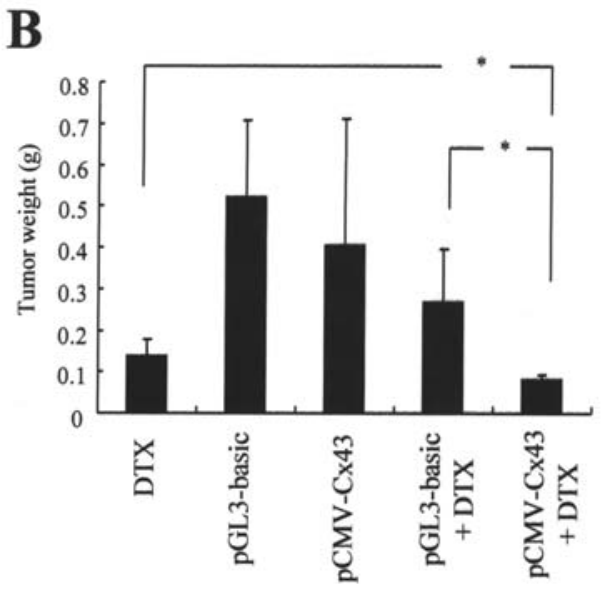

Figure 6. In vivo combination therapy of PC-3 tumor xenografts with $\mathrm{Cx} 43$ and DTX in mice. When the average volume of PC-3 xenograft tumors reached $200 \mathrm{~mm}^{3}$ (day 0), these mice were selected for treatment with DTX alone, pGL3-basic, pCMV-Cx43, pGL3-basic plus DTX and pCMV-Cx43 plus DTX. Nanoplexes of $10 \mu \mathrm{g}$ plasmid per tumor were directly injected into xenografts on days 0 and 1 . DTX at a dose of $15 \mathrm{mg} / \mathrm{kg}$ was injected i.v. on days 0 . Tumor volume (A) was measured on days $0,3,6,9,11,13,15$. On day 15 , all mice were sacrificed, the tumor weight (B) was measured and macroscopic tumor appearance (C) was evaluated. Data are shown as the mean \pm SE (A) or mean \pm SD (B). $n=4$ for each group. ${ }^{*} \mathrm{p}<0.05$. deliver DNA into PC-3 xenografts (28). Therefore, we used $\mathrm{NP}$ as a DNA transfection vector for in vivo experiment. The anti-tumor effect was evaluated by direct injection of the nanoplex of pCMV-Cx43 or pGL3-basic into the xenografts once a day on two occasions (day 0 and 1 ) following one i.v. injection of DTX (day 0) according to a previous report on in vivo combination gene therapy with DTX (29). No significant decrease in tumor weight was observed in mice treated with pCMV-Cx43 (Fig. 6B). A growth inhibitory effect was observed in mice treated with DTX alone or
pGL3-basic plus DTX compared with control mice (Fig. 6A and B). pGL3-basic plus DTX exhibited a similar tumor suppressive effect with DTX alone, indicating that DNA transfection did not increase tumor growth inhibition. A significant growth inhibitory effect was observed in combination therapy of pCMV-Cx43 and DTX compared with DTX alone (Fig. 6A and B). A comparison of tumor weight and the appearance after excision also demonstrated that tumor growth was attenuated in mice treated with pCMV-Cx43 and DTX (Fig. 6B and C). 


\section{Discussion}

The limited efficacy of cytotoxic chemotherapy remains a major problem in the treatment of advanced hormone-refractory prostate cancer (30); therefore, novel cancer gene therapy needs to be developed. In this study, we found that $\mathrm{Cx} 43$ expression in PC-3 cells significantly enhanced DTX cytotoxicity through down-regulation of Bcl-2 expression and activation of the apoptosis pathway. Furthermore, the combination of non-viral Cx43 gene therapy and DTX significantly suppressed the growth of tumor xenografts compared to DTX alone. This is the first report to highlight that the expression of Cx43 in association with DTX has potential as a tumor growth inhibitor.

Dysregulation of Cx expression is thought to be associated with carcinogenesis; however, there is relatively little information regarding the mechanism of altered $\mathrm{Cx}$ expression in prostate cancer. The tumor-suppressing effects of $\mathrm{Cx}$ genes largely depend on the Cx species and the cell types used (31). Transduction of $\mathrm{Cx} 32$ and $\mathrm{Cx} 43$ by retroviral gene transfection into the $\mathrm{Cx}$-deficient prostate cancer cell line $\mathrm{LNCaP}$ produced growth inhibition in vitro and in vivo, and cell differentiation associated with gap junction formation (19). Transduction of Cx26 by adenoviral gene transfection into LNCaP and PC-3 cells produced growth inhibition by a GJIC function (26). Regarding Cx43, the expression of $\mathrm{Cx} 43$ in PC-3 cells could not form gap junctions (32). In our study, the transfection of pCMV-Cx43 into PC-3 cells exhibited neither the inhibition of cell growth nor increased GJIC (Fig. 1); however, transfection into the cells increased apoptotic cells and caspase- 3 activity (Fig. 5). Cx43 expression in PC-3 cells might regulate apoptosis via a GJIC-independent mechanism.

Combination therapy of Cx43 and DTX was significantly more cytotoxic when cells were treated with DTX $24 \mathrm{~h}$ after Cx43 transfection compared with treatment with DTX and transfection at the same time. It suggested that $\mathrm{Cx} 43$ expression $24 \mathrm{~h}$ after transfection affected sensitivity to DTX. We also found that combination therapy $72 \mathrm{~h}$ after transfection increased growth inhibition in $\mathrm{LNCaP}$ cells $\left(\mathrm{IC}_{50}\right.$ for DTX $=32$ and $4.2 \mathrm{ng} / \mathrm{ml}$ in pGL3-basic- and pCMV-Cx43-transfected cells, respectively) (data not shown). Combination therapy using the $\mathrm{Cx}$ gene and chemotherapeutic agents for cancer has been reported. Cx43 transfected into human glioblastoma cells (20) and ovarian carcinoma cells (21) led to the down-regulation of Bcl-2 and increased sensitivity to paclitaxel and doxorubicin. In our study, DTX treatment caused an increase in $\mathrm{G}_{2} / \mathrm{M}$ populations into PC-3 cells (Fig. 3C), and also induced the down-regulation of $\mathrm{Bcl}-2$ expression and up-regulation of caspase-3 activity in PC-3 cells (Figs. 4 and 5). This finding corresponds with previous reports that DTX induced the down-regulation of $\mathrm{Bcl}-2$ expression in prostate tumor $\mathrm{LNCaP}$ and PC-3 cells $(33,34)$, and that down-regulation of Bcl-2 expression by $\mathrm{Bcl}-2$ antisense activated caspase- 3 activity in PC-3 cells (35). Combination therapy of pCMV-Cx43 and DTX increased $\mathrm{G}_{2} / \mathrm{M}$ populations, enhancing down-regulation of Bcl-2, and growth inhibition in vitro more than DTX alone.

The combination of repeated intratumoral injections of pCMV-Cx43 (10 $\mu \mathrm{g} /$ tumor) with non-viral vector and a single intravenous injection of DTX (15 mg/kg) was compared with a repeated injection of $\mathrm{Cx} 43$ alone and a single injection of DTX alone in PC-3 tumor xenografts. Significant antitumoral effects were observed in mice receiving combined treatment, compared with DTX alone. The efficacy in vivo might result from direct effects of $\mathrm{Cx} 43$ on inducing apoptosis and indirect effects on enhancing the cytotoxicity of DTX by down-regulating Bcl-2. It has been reported that paclitaxel increased the transfection efficiency of cationic liposome by inhibiting targeting endosomes to lysosomes $(36,37)$. Therefore, using the combined lipid-mediated transfection of genes with DTX for cancer gene therapy might be a powerful technique due to the effect of enhanced gene expression. Inhibiting Bcl-2 expression by $\mathrm{Cx} 43$ in prostate cancer cells, which could restore their sensitivity to chemotherapeutic agents, would be a new therapeutic strategy against prostate cancer.

From a clinical point of view, the doses of DTX used in the combined strategy will be minimal, and will prevent significant toxicity due to DTX. Low doses of DTX can thus be administered in humans for a prolonged period of time, or alternatively, a shorter duration of combined treatment may be administered without loss of effectiveness. Enforced expression of $\mathrm{Cx} 43$ increased sensitivity for DTX via the down-regulation of Bcl-2 expression in PC-3 cells. Combining non-viral Cx43 gene therapy with DTX resulted in greater growth suppression of PC-3 in vitro and in vivo. The data presented here provide a rational strategy for treating patients with advanced hormone refractory prostate cancer.

\section{Acknowledgements}

This project was supported in part by a grant from The Promotion and Mutual Aid Corporation for Private Schools of Japan, and by a Grant-in-aid for Scientific Research from the Ministry of Education, Culture, Sports, Science, and Technology of Japan.

\section{References}

1. Gao X, Porter AT, Grignon DJ, Pontes JE and Honn KV: Diagnostic and prognostic markers for human prostate cancer. Prostate 31: 264-281, 1997.

2. Oh WK and Kantoff PW: Management of hormone refractory prostate cancer: current standards and future prospects. J Urol 160: 1220-1229, 1998.

3. Syed S: Combination chemotherapy for hormone-refractory prostate carcinoma: progress and pitfalls. Cancer 98: 2088-2090, 2003.

4. Beer TM, El Geneidi M and Eilers KM: Docetaxel (taxotere) in the treatment of prostate cancer. Expert Rev Anticancer Ther 3: 261-268, 2003.

5. Hong WK: The current status of docetaxel in solid tumors. An M.D. Anderson Cancer Center Review. Oncology 16: 9-15, 2002.

6. Pienta KJ: Preclinical mechanisms of action of docetaxel and docetaxel combinations in prostate cancer. Semin Oncol 28: 3-7, 2001

7. Li Y, Li X, Hussain M and Sarkar FH: Regulation of microtubule, apoptosis, and cell cycle-related genes by taxotere in prostate cancer cells analyzed by microarray. Neoplasia 6: $158-167,2004$.

8. Knuechel R, Siebert-Wellnhofer A, Traub O and Dermietzel R: Connexin expression and intercellular communication in twoand three-dimensional in vitro cultures of human bladder carcinoma. Am J Pathol 149: 1321-1332, 1996.

9. Bruzzone R, White TW and Paul DL: Connections with connexins: the molecular basis of direct intercellular signaling. Eur J Biochem 238: 1-27, 1996. 
10. Tsai H, Werber J, Davia MO, et al: Reduced connexin 43 expression in high grade, human prostatic adenocarcinoma cells. Biochem Biophys Res Commun 227: 64-69, 1996.

11. Hossain MZ, Jagdale AB, Ao P, LeCiel C, Huang RP and Boynton AL: Impaired expression and posttranslational processing of connexin43 and downregulation of gap junctional communication in neoplastic human prostate cells. Prostate 38: 55-59, 1999.

12. Habermann H, Ray V, Habermann W and Prins GS: Alterations in gap junction protein expression in human benign prostatic hyperplasia and prostate cancer. J Urol 167: 655-660, 2002.

13. Mehta PP, Lokeshwar BL, Schiller PC, Bendix MV, Ostenson RC, Howard GA and Roos BA: Gap-junctional communication in normal and neoplastic prostate epithelial cells and its regulation by cAMP. Mol Carcinog 15: 18-32, 1996.

14. Yamasaki H: Role of disrupted gap junctional intercellular communication in detection and characterization of carcinogens. Mutat Res 365: 91-105, 1996.

15. Chen SC, Pelletier DB, Ao P and Boynton AL: Connexin43 reverses the phenotype of transformed cells and alters their expression of cyclin/cyclin-dependent kinases. Cell Growth Differ 6: 681-690, 1995.

16. Huang RP, Fan Y, Hossain MZ, Peng A, Zeng ZL and Boynton AL: Reversion of the neoplastic phenotype of human glioblastoma cells by connexin 43 (cx43). Cancer Res 58: 5089-5096, 1998.

17. Hirschi KK, Xu CE, Tsukamoto $\mathrm{T}$ and Sager R: Gap junction genes $\mathrm{Cx} 26$ and $\mathrm{Cx} 43$ individually suppress the cancer phenotype of human mammary carcinoma cells and restore differentiation potential. Cell Growth Differ 7: 861-870, 1996.

18. Zhang ZQ, Zhang W, Wang NQ, Bani-Yaghoub M, Lin ZX and Naus CC: Suppression of tumorigenicity of human lung carcinoma cells after transfection with connexin43. Carcinogenesis 19: 1889-1894, 1998.

19. Mehta PP, Perez-Stable C, Nadji M, Mian M, Asotra K and Roos BA: Suppression of human prostate cancer cell growth by forced expression of connexin genes. Dev Genet 24: 91-110, 1999.

20. Huang RP, Hossain MZ, Huang R, Gano J, Fan Y and Boynton AL: Connexin 43 (cx43) enhances chemotherapyinduced apoptosis in human glioblastoma cells. Int J Cancer 92: $130-138,2001$

21. Fernstrom MJ, Koffler LD, Abou-Rjaily G, Boucher PD, Shewach DS and Ruch RJ: Neoplastic reversal of human ovarian carcinoma cells transfected with connexin 43. Exp Mol Pathol 73: 54-60, 2002.

22. Hattori Y and Maitani Y: Folate-linked nanoparticle-mediated suicide gene therapy in human prostate cancer and nasopharyngeal cancer with herpes simplex virus thymidine kinase. Cancer Gene Ther 12: 796-809, 2005.

23. Igarashi S, Hattori $\mathrm{Y}$ and Maitani $\mathrm{Y}$ : Biosurfactant MEL-A enhances cellular association and gene transfection by cationic liposome. J Control Release 112: 362-368, 2006.

24. Robe PA, Jolois O, N'Guyen M, Princen F, Malgrange B, Merville MP and Bours V: Modulation of the HSV-TK/ ganciclovir bystander effect by n-butyrate in glioblastoma: correlation with gap-junction intercellular communication. Int J Oncol 25: 187-192, 2004.
25. Hattori Y, Kubo H, Higashiyama K and Maitani Y: Folatelinked nanoparticles formed with DNA complexes in sodium chloride solution enhance transfection efficiency. J Biomed Nanotech 1: 176-184, 2005.

26. Tanaka $\mathrm{M}$ and Grossman HB: Connexin 26 induces growth suppression, apoptosis and increased efficacy of doxorubicin in prostate cancer cells. Oncol Rep 11: 537-541, 2004.

27. Fujimoto E, Sato H, Nagashima Y, et al: A Src family inhibitor (PP1) potentiates tumor-suppressive effect of connexin 32 gene in renal cancer cells. Life Sci 76: 2711-2720, 2005.

28. Hattori Y and Maitani Y: Two-step transcriptional amplificationlipid-based nanoparticles using PSMA or midkine promoter for suicide gene therapy in prostate cancer. Cancer Sci 97: 787-798, 2006.

29. Hayashi N, Asano K, Suzuki H, Yamamoto T, Tanigawa N, Egawa $\mathrm{S}$ and Manome $\mathrm{Y}$ : Adenoviral infection of survivin antisense sensitizes prostate cancer cells to etoposide in vivo. Prostate 65: 10-19, 2005.

30. Kasamon KM and Dawson NA: Update on hormone-refractory prostate cancer. Curr Opin Urol 14: 185-193, 2004.

31. Mesnil M, Krutovskikh V, Piccoli C, Elfgang C, Traub O, Willecke $\mathrm{K}$ and Yamasaki H: Negative growth control of HeLa cells by connexin genes: connexin species specificity. Cancer Res 55: 629-639, 1995.

32. Govindarajan R, Zhao S, Song XH, Guo RJ, Wheelock M, Johnson KR and Mehta PP: Impaired trafficking of connexins in androgen-independent human prostate cancer cell lines and its mitigation by alpha-catenin. J Biol Chem 277: 50087-50097, 2002.

33. Tang Y, Khan MA, Goloubeva O, Lee DI, Jelovac D, Brodie AM and Hussain A: Docetaxel followed by castration improves outcomes in LNCaP prostate cancer-bearing severe combined immunodeficient mice. Clin Cancer Res 12: 169-174, 2006.

34. Muramaki M, Miyake H, Hara I and Kamidono S: Synergistic inhibition of tumor growth and metastasis by combined treatment with TNP-470 and docetaxel in a human prostate cancer PC-3 model. Int J Oncol 26: 623-628, 2005.

35. Yamanaka K, Rocchi P, Miyake H, Fazli L, Vessella B, Zangemeister-Wittke $U$ and Gleave ME: A novel antisense oligonucleotide inhibiting several antiapoptotic Bcl-2 family members induces apoptosis and enhances chemosensitivity in androgen-independent human prostate cancer PC3 cells. Mol Cancer Ther 4: 1689-1698, 2005.

36. Hasegawa S, Hirashima N and Nakanishi M: Microtubule involvement in the intracellular dynamics for gene transfection mediated by cationic liposomes. Gene Ther 8: 1669-1673, 2001.

37. Nair RR, Rodgers JR and Schwarz LA: Enhancement of transgene expression by combining glucocorticoids and antimitotic agents during transient transfection using DNA-cationic liposomes. Mol Ther 5: 455-462, 2002. 